\title{
Complication of endoscopic papillary large-balloon dilation using double-balloon endoscopy for biliary stones in a postoperative patient
}

Recently, extraction of stones by endoscopic papillary large-balloon dilation (EPLBD) using CRE balloons (Boston Scientific Japan, Tokyo, Japan; $5.5 \mathrm{~cm}$ long, 10 $12,12-15$, and $15-18 \mathrm{~mm}$ in diameter) has been shown to be an effective modality, which is being widely used in difficult situations for patients with normal anatomy [1,2]; however, few papers have reported on the use of EPLBD in patients with altered gastrointestinal anatomy [35], and fewer still on its complications.

In the present report, we describe a rare and instructive adverse event that was encountered during the procedure and was recorded on video as it occurred. These recordings show the development of an iatrogenic fistula.

A 71-year-old man with a history of gastric ulceration who had undergone a Billroth II gastrectomy 45 years previously was admitted with jaundice and acute cholangitis. He was referred for stone extraction using endoscopic retrograde cholangiopancreatography (ERCP) using a short-type double-balloon endoscope (DBE; EI-530B, Fujifilm, Osaka, Japan). The DBE advanced smoothly to the blind end and deep cannulation was successful ( Video 1).

The cholangiogram revealed large biliary stones in the lower biliary duct. Therefore stone extraction was planned in combination with endoscopic sphincterotomy and EPLBD. After we had inserted a 0.035-inch guidewire (Jagwire; Boston Scientific Japan, Tokyo, Japan), a limited endoscopic sphincterotomy, involving one-third of the maximum incision of the papillary mound, was performed using a standard pull-type papillotome (Clevercut KDV411M-3020; Olympus Medical Systems) ( Video 2). Balloon dilation was performed slowly under fluoroscopy guidance until the notch disappeared ( Video 3 ).

The complication occurred while we were performing EPLBD. An iatrogenic fistula developed, which was caused by a stone that was jutting out from the papillary mound and dilatation of the lower biliary duct due to overlooked stones ( $\bullet$ Video 4). Despite this adverse event, stone extraction was accomplished, and the procedure was completed by placement of an endoscopic biliary drain (ZEBD-5-4; Cook Medical, Bloomington, Indiana, USA) and nasal biliary drain (ENBD-5; Cook Medical) ( Video 5). The patient improved with further conservative management. However, we note that if the fistula had developed on the pancreatic side, it could have caused compression of the pancreas leading to severe complications, such as acute or severe pancreatitis.

We believe stone extraction using EPLBD in patients with altered gastrointestinal anatomy is more difficult and poses a higher risk than it would in patients with normal anatomy. Therefore analysis of the adverse events is needed before this technique can be established as a safe procedure.

\section{Video 1}

The papilla was positioned in the 6-o'clock position on the monitor and biliary cannulation was performed using a straight-tipped catheter.

\section{Video 2}

After inserting a guidewire, we performed a limited endoscopic sphincterotomy, involving onethird of the maximum incision of the papillary mound, using a standard pull-type papillotome.

\section{Video 3}

Endoscopic papillary large-balloon dilation (EPLBD) was performed slowly until the notch disappeared under fluoroscopy guidance.

\section{Video 4}

While we were performing endoscopic papillary large-balloon dilation (EPLBD), an iatrogenic fistula developed due to a stone that was jutting out from the papillary mound.

\section{Video 5}

Stone extraction was accomplished and then the procedure was completed by placement of an endoscopic biliary drain and a nasal biliary drain.
Competing interests: None

Masaaki Shimatani, Makoto Takaoka, Toshiyuki Mitsuyama, Hideaki Miyoshi, Tsukasa Ikeura, Kazuichi Okazaki

Third Department of Internal Medicine, Kansai Medical University, Osaka, Japan

\section{References}

1 Heo JH, Kang DH, Jung HJ et al. Endoscopic sphincterotomy plus large-balloon dilation versus endoscopic sphincterotomy for removal of bile-duct stones. Gastrointest Endosc 2007; 66: 720-726

2 Meine GC, Baron TH. Endoscopic papillary large-balloon dilation combined with endoscopic biliary sphincterotomy for the removal of bile duct stones (with video). Gastrointest Endosc 2011; 74: 1119-1126

3 Jang HW, Lee KJ, Jung MJ et al. Endoscopic papillary large balloon dilatation alone is safe and effective for the treatment of difficult choledocholithiasis in cases of Billroth II gastrectomy: a single center experience. Dig Dis Sci 2013; 58: 1737-1143

4 Choi CW, Choi JS, Kang DH et al. Endoscopic papillary large balloon dilation in Billroth II gastrectomy patients with bile duct stones. J Gastroenterol Hepatol 2012; 27: 256-260

5 Shimatani M, Takaoka M, Matsushita M et al. Endoscopic approaches for pancreatobiliary diseases in patients with altered gastrointestinal anatomy. Dig Endosc 2014; 26: $70-78$

\section{Bibliography}

DOI http://dx.doi.org/

10.1055/s-0034-1377387

Endoscopy 2014; 46: E390

(c) Georg Thieme Verlag KG

Stuttgart · New York

ISSN 0013-726X

\section{Corresponding author}

\section{Shimatani, MD}

Third Department of Internal Medicine

Kansai Medical University

2-5-1 Shinmachi, Hirakata

Osaka 573-1010

Japan

Fax: +81-72-8042524

shimatam@hirakata.kmu.ac.jp 